\title{
Euclidean Embodiments in the Twenty-First Century: An Allegorical Ode to Aldous Huxley (1894-1963)
}

\author{
Bharath Sriraman ${ }^{1}$ (D)
}

Received: 17 April 2021 / Accepted: 12 October 2021 / Published online: 27 October 2021

(C) The Author(s), under exclusive licence to Springer Nature B.V. 2021

\begin{abstract}
An allegorical thought experiment occurring in a pseudo Huxleyean world in the future is conducted, in which "Euclidean" geometry has been forgotten and can only be retrieved by traversing backward in time, physically and virtually by two protagonists, Alpha and Beta, inspired by the challenge issued by their teacher Aleph 1. In the year 136 A.H (After Huxley, or late twenty-first century of the Common Era), all instruction occurs virtually. Mathematics is the exclusive purview of $0.01 \%$ of society (the alphas). The thought experiment leads to the discovery and realization from the two protagonists that Euclidean geometry is possible using sensorimotor functions with tools called a straight edge and compass or simply a rope with knots. As an ode to Aldous Huxley (1894-1963) this article is deliberately in the form of a satirical provocation that examines the interaction of technology with the learning of mathematics in a dystopian future. A prolog explaining the context of the thought experiment along with a coda with implications for the immediate future in the learning of mathematics is made. A glossary with terms unfamiliar to the reader is also provided.
\end{abstract}

Keywords Aldous Huxley · Creativity · Creative fiction · Euclid · Egypt ·

Geometry $\cdot$ Lorentz transformation · Mathematics · Mathematics fiction · Nubians ·

Technology $\cdot$ Thought experiment $\cdot$ Learning of mathematics

\section{Prolog}

For the uninitiated Aldous Huxley (1894-1963) was one of the leading twentieth century intellectuals who contributed to both literature and philosophy. Even though his name has become synonymous with the novel Brave New World, he devoted considerable amounts of time to finding common ground between Eastern and Western mysticism and developing a corpus of work on philosophical mysticism. The

Bharath Sriraman

sriramanb@mso.umt.edu

1 Department of Mathematical Sciences, University of Montana, Missoula, USA 
allegorical thought experiment in the ensuing sections of article assumes the reader has no familiarity with Huxley's Brave New World. This assumption requires the elaborate set up of the thought experiment in a pseudo Huxleyean world. Satirical allusions are made to real and impending events in our past and current world history with the goal of situating it within current scientific, technological, environmental and political dilemmas confronting humanity. No assumptions are made on the reader's mathematical sophistication even though terms from "String theory" are liberally used albeit in a satirical fashion.

\section{Introduction: 136 A.H}

The year is One hundred and Thirty-Six After Huxley (A.H). The Common Era ended one hundred and thirty six years ago with the demise of the Universal Father Aldous Huxley, ushering in the Huxley Era, where humans had quickly mutated into humanoids on what remained of the planet. A virtual classroom on "higher mathematics" is taking place in the rainforest of former Queensland, now renamed Gondwanaland $^{1}$ - the land of dreamtime, aboriginal time. There is one beta in a sea of alpha students, allowed to enroll in the advanced mathematics course to diversify the learning environment. After the cataclysmic upheavals of the Common Era, and the Aldebaranian revelations received by the Universal Father, huxleyfication had distilled society into four classes, namely the alphas, the betas, the thetas and lambdasa recreation of the order of society according to the ancient laws of Manu. Human society as known in the Common Era no longer existed. Climate Change, the Refugee Crisis, Pandemics, Nuclear war and a new geography created by turbulent polar seas and hyper- thunder tornados had served the new world order (the Aldebaranian Politburo) in its mass displacement efforts. A genius from the alpha class had discovered the law "Replace the displaced volume of the land masses with an equal volume of people elsewhere", now known as the Alpha law of land buoyancy.

The alphas constituted $0.01 \%$ of the world population that produced the thinkers, innovators, leaders, social engineers, environmental hackers, consciousness manipulators, bio-geneticists, professors; surgeons; virtual programmers, artists and the fashionably bored necessary to keep order within their small community. The betas were $29.99 \%$ of the population genetically engineered to care for the population from cradle to grave. They provided goods and services in the sectors of nursery, teaching, critical health care, horticulture, gerontology and many others. The thetas (thugs and delivery services) and lambdas (general laborers) each constituted 30\% of the population, differentiated by eye color- the former being brown with black hair, and the latter being blue with blond hair. Every blond haired, blue-eyed child in 136 A.H was destined for a fulfilling lifetime of diligent labor. The alphas were black eyed, and the betas green eyed. Moreover, there were mutants who accounted for the remaining $10 \%$ of the population.

\footnotetext{
1 All italicized terms are defined in the Glossary at the end of the chapter.
} 


\section{The Teacher: Aleph 1}

Aleph 1 was born into the beta class but the Diversification (lottery) Act in 46 A.H had allowed her to access education hitherto only available to the alphas. In physical terms, she belonged to a group formerly known as the Kurds, an ancient and fiercely independent people left with no homeland in the B.H.E (Before Huxley Era) due to the heinous geopolitics enacted by the lambdas for half a millennium of the Common Era. It had taken not only a mind revolution but mass displacement of people from different continents to ensure that no place on the planet had a "majority" of peoples or a disgruntled minority that created strife, except for the mutant zone. Advanced bioengineering and womb-based genetics replicated on five generations had finally produced a world order in which four groups of humanoids existed peacefully, following the ancient laws of Мanu. The archaic idea of place based or institutionalized education had been replaced for $99.99 \%$ of the population by unconscious mental programming administered in nurseries for 21,024 $\mathrm{h}$ from birth to the age of six, during the time spent sleeping when the brain was open for programming.

Mutants were a rare occurrence in the sixth iteration of humanoids currently on the planet. However earlier incarnations (or iterations of womb-based genetics) resulted in humanoids that were on the cusp of two classes such as our teacher Aleph 1 (An alpha-beta), who also retained collective memories of the physical location of their ancestors and residual individual consciousness that made them particularly dangerous and prone to heresy. Mutants born at the cusp of the alphas and betas received "special classification" in the Diversification (lottery) Act. They were placed in schools for the alphas with the hope of creating an Aldebaranian identity that prevented them from regressing into heretical tendencies.

Aleph 1 was now in her early90s -the golden years for teachers to offer elective courses unavailable in the regular virtual photo-plasma for alphas. She decided to offer a course in "Higher Geometry" inspired by the memory of a physical book she had read as a child called "The Higher Arithmetic" (Davenport, 1952).

\section{The Students- From Cradle to Grave}

The thetas and lambdas completed their education at the ages of ten and eight respectively. The "programming treatment" mentioned earlier was uniform for both groups until the age of six. After this, a regimen of physical training and growth hormone treated maggot protein formed the daily staple for thetas until the age of nine and lambdas until the age of seven. The thetas ended their education with a year of finishing school in hand combat like Kalaripayyattu and Tahtib; and nightly brainwashing in following orders that would be telepathically transmitted for the rest of their lives. At the age of 10, thetas entered the work force following the Teutonic tradition of Wanderjahre (journeyman) and wandered for three years and one day in different constituencies to garner experience 
and determine fit. The first year was a mandatory posting in Xinjiang (known as Western China in the Common Era), which had become a lawless zone for the nearly million or so mutants - unfortunate byproducts of the first five iterations of the Huxley Era. This group ( with the exception of the alpha-beta mutants that benefitted from the diversification lottery) did not fit into any of the four classes of alphas, betas, thetas and lambdas and hence were relegated to the wastelands where they could live in the way Nature had intended, presumably a B.H.E primitive concept.

The lambdas unlike the thetas finished the last year of their schooling cultivating fine motor and gross motor skills needed for various professions (cobblers, tailors, quarry workers. tannery workers, metalsmithing, masons, weed workers, tillers, millers, farm laborer, cooks etc.). Manual labor was the de facto source of work for the lambdas. Both groups, the thetas and lambdas, starting at the age of 15 were programmed to be highly promiscuous and encouraged to have as many children as possible. These children were raised by the State as long as they were not mutant. At the age of 55, a pre-programmed mental suggestion led members of both these groups to undertake a one-way pilgrimage to one of seven selected places on the planet. These selected places called "Wonders of Rebirth" were the sites of barbaric traditions such as: (1) jumping or being thrown off cliffs; (2) freezing to death; (3) dying of poisonous bites and (4) heat exhaustion. These were common occurrences two millennia Before Huxley. For the curious reader, these places bore the former names of Greece, Ireland, Norway, Malaysia, Greenland, Italy and Saudi Arabia.

Unlike the thetas and lambdas, the betas received schooling until the age of 18 and the alphas had no limits in the length of their schooling. The betas finished their last year of schooling with "empathy training" which had a practicum in the field. Most alphas stopped at the age of 21 to pursue the ancient tradition of being fashionably bored, whereas some of the more precocious alphas carried on studying well into their $30 \mathrm{~s}$. Aleph 1 had studied until the age of 40, thereby earning the rank of Mother Bee in the Hermitian University of Free Thought. She was a spinster who had dedicated her life not only to reconstructing a handloom to spin her clothes, but also to recreating Collective Consciousness 1.0, namely the lost knowledge and practices of the Before Huxley Era. The former- spinning was sanctioned by the Politburo as a useful meditative exercise for everyone including the fashionably bored, but the latter was an unsanctioned project.

\section{The Classroom}

Mother Bee was lecturing on setting the context of "Higher Mathematics". She said:

In the Before Huxley Era (B.H.E), the ubiquity or invasiveness of data with the day-to-day living ranged from primitive information technology devices used for communication to instructional modes online to financial transactions. The pandemics brought to the forefront of society the language of mathematics, in the models used in the popular media of that time-period to describe the spread of the viruses, and in debates about the 
sensitiveness of data when harvested through contact tracing. Mathematics and ethics became inter-twined in the types of questions increasingly posed by that primitive society in relation to the use, misuse and abuse of data (personal, medical, financial, educational etc.,) but led to unchecked malevolent creativity perpetuated by the lambdas. The lambdas were on the cusp of not only complete planetary dominance through mass human engineering and subconscious manipulations but also harvested all possible data available until that point of time. The Polar Flood theory suggests that all this data was lost in the cataclysm of fire and flood that plagued the world for two score years and rid the world of banal technology called the Internet. In our course, we do not rely on any such archaic bibliometric repositories but will use Photo-plasma technology to virtually navigate our world of available knowledge to recreate Geometry in its purest and highest form. All of you have passed the entrance exam in Hermitian operator theory and String theory, and qualified to advance yourselves in this capstone course in mathematics.

\section{Interrupting Aleph 1}

Alpha: Mother Bee- you have not really gone into the data analytic techniques that led to malevolent creativity in the B.H.E. The lambdas came up with subjective metrics based on sophisticated Monte Carlo methods and Time Series analysis of digital traces of people to formulate measures for "likeability", "job worthiness", "symmetry profile" (a marker for "beauty", "mate/spouse worthiness") etc., which in turn determined the socio-economic status of individuals. The mathematics of that time-period was applied to create an invisible wall where archaic perceptions of upward mobility between classes, and higher socio-economic status continued for the masses but they were no longer based on education or professional achievement, but entirely on arbitrary measures based on the new mores of that society engineered by the lambdas.

Aleph 1: Yes, and we all know what lambdas are good for now!

\section{Laughter}

Beta: The humans were a data hungry species unlike us. Surveillance and other facial recognition technologies were also continually harvesting data that created a digital footprint of all human movement in some countries. Underneath these strictly "physical" sources of data lay a deeper web of communication, in transactions that occurred on a daily basis and information seeking - these were richer sources of data that were harvested for analysis of browsing habits, shopping/spending habits, texting habits, patterns of speech etc. Their world was trans-mutating into one where every decision made by and made for people was driven by data analytics, and could in fact be predicted.

\section{Collective Laughter in Classroom}

Aleph 1: Silence. Do you have anything else to add before I proceed with the agenda for the course? 
Beta: Yes. One last thing. In some reruns of programming from that timeperiod about their future-now the topic of a new documentary series, one sees episodes where futuristic "after life" services are promised based on the sum total of the harvest of one's net-presence to recreate a virtual version of a person after their demise based on the analysis of their habits. It seems that the world they were creating was in fact prophesized by our Universal Father Aldous Huxley in his writings- particularly A Brave New World.

Aleph 1: Maybe so- but they obviously made a real mess out of it. Interesting points from both Alpha and Beta but these matters are not the focus of this course. Applied statistical methods and voyeuristic historical film experiences with past media are tangential to the concerns of this class. What we are aiming to answer in this course is the following question for which three years (with an extra year if needed) of either virtual or physical traveling (in special cases) are the only creative resources available.

\section{Murmur in the Classroom}

Aleph 1: Listen carefully. I shall only utter the questions once. Did there exist a Geometry done with hand-held tools? Did this geometry act as the seed for completely abstract geometry?

Beta: You mean using haptic hand-held devices or magneto mind eurhythmy for topologically manipulating homeomorphic objects?

\section{Laughter}

Aleph 1: No, I meant mechanical hand held devices that work without connectivity, magnetism or electricity.

\section{Collective gasp in the classroom}

Alpha: This means it would exist outside the photo plasma and plasma-net.

Aleph 1: Not necessarily- maybe there is knowledge within it ... sources that point to the existence of such a geometry.

Beta: The only geometry available on the plasma-net is related to Calabi-Yau manifolds, used to predict additional dimensions in the universe using string theory in the B.H.E.

Aleph 1: When you traverse our world, do you see any physical evidence of Calabi-Yau manifolds?

\section{Laughter}

Beta: Pipelines meet at a space called a manifold. I recall seeing a picture of a B.H.E petroleum platform, where pipelines converged on the platform at a manifold.

Aleph 1: You got me there. I meant abstract manifolds.

Alpha: There are also archaic references on the plasma-net to space-time geometry developed by Hermann Minkowski in the B.H.E. This evidently laid 
the foundations for special relativity and then led to speculations about general relativity. Manifold geometry using tensors became the language of this theory.

Aleph 1: The incompatibility of general relativity with quantum physics was already well known back then to the primitives. You may want to look at the geometry of four dimensional pseudo- Riemannian manifolds. Special relativity may also be a good starting point for your journey. Any more questions?

Beta: Are we looking for measurable geometries?

Aleph 1: To measure or not to measure - that is the question. Does the plasmanet haveinformation on the meaning of the word Geometry?

Beta: It states Geometry is an undefined term.

\section{Collective Gasp}

Aleph 1: I need to be transparent with you as you embark on answering my questions. The questions are meant to lead you into the pursuit of a meaningful life in your $30 \mathrm{~s}$ and to higher learning. There are numerous gaps in our short history, especially the early years of our civilization when nuclear warheads triggered in the former United States, China and Pakistan coupled with the 20 year Internet Guerilla Trojan War masterminded in lawless territories resulted in an almost complete annihilation of the so-called Internet and other technologies that shaped the previous civilization. It took the ingenuity of our African and Indian ancestors to revive and build civilization, as we know it today. The photo-plasma and the plasma-net are incomplete and do not contain all the information you may need to answer the question.

\section{Another Large Collective Gasp}

Aleph 1: Yes, I have been authorized to release this classified information. Our goal is for this class of alphas to start the next revolution needed for humanoid civilization to undergo the final revolution necessary for perpetual survival.

The class concludes. Beta and Aleph 1 meet in a virtual six-dimensional Calabi Yau portal that includes all the former five human senses and a sixth plasma sense for virtual navigation.

Beta: Mother Bee, you do realize I am not an alpha.

Aleph 1: Yes, nor am I.

Beta: Do I present a danger to society by embarking on this research question? I do not want to be labeled a heretic.

Aleph 1: On the contrary. Our hope is to regenerate what was once known as "Collective Consciousness 1.0" based on the remnant knowledge and memories of the peoples that were lost in the cataclysms of the Common Era.

Beta: How does the question about Geometry relate to this? Wouldn't a virtual archaeological expedition yield more answers?

Aleph 1: Do you know who you are?

Beta: That is a tautological question. I am a Beta. 
Aleph 1: I was $a$ Beta too- but I also know that I was born in a Kurdish village devastated during the last upheavals of the Common Era. I remember who my parents and grandparents were as well as all the books that were available to us for learning. Let me rephrase my question in terms you would understand. What are you?

Beta: I am Beta raised in Lyceum 49, located in the outer regions of Zululand. I do not know my parents nor my grandparents, nor do I remember the presence of any physical books during my initial schooling.

Aleph 1: Precisely. You are in fact an alpha-beta mutant like me. Your father was a refugee alpha Dravidian from the lost island of Lanka, and your mother was a beta from Zululand. I was a mutant too- my parents came from places known as Turkey and Iran in the Common Era. I am unsure who was the alpha? I was told that my mother was the alpha. It doesn't matter. Our future rests in finding a way for the million mutants that I call the Dreamers. They still exist in what our aboriginal fore fathers named the Dreamtime but are lost in perpetual warfare due to the abysmal conditions of their region. My last remaining goal is to establish new Lyceums there, which exists independent of the photo-plasma and the plasma-net, and where schooling can create the next generation of teachers like me who can lead us into a collective future.

Beta: May I choose the physical option instead of the virtual option as my creative tool.

Aleph 1: Certainly, but be warned it will be much more difficult.

\section{Alphas Virtual Journey into Geometric Rabbit Holes: Two Years Later}

The plasma-net did not contain any relevant sources within its repository of mathematics. Alpha had spent two years mining through the plasma-net scanning through all the existing mathematics books. One word that occurred in every million mathematical words was the term "Euclidean". The term was used in reference to an advance that had been made in relation to what existed before, without any detail of what had existed before. Alpha began to cultivate the vague suspicion that the plasma-net had been haphazardly cobbled with purposeful deletions of certain topics, which fell under the "undefined" category. Both "geometry" and "religion" were undefined terms. No clear trace into the past was possible with either of these terms. At the Hermitian University of Free Thought, the study of geometry began with revolutions in String theory and ended with the geometry of Minkowski classified as "primitive." The former was used to establish the presence of Aldebaran as the All Knowing Deity that lived in the 11th dimension outside the 10 dimensions of the Universe; and the latter made decomposition of mass in time travel possible with the risk of never getting recomposed. Three time travelers had never returned and served as a warning for others tempted to engage in such travel. All this was barely two centuries of mathematics. Surely, humans in the B.H.E who developed the fantastical applied data analytic methods were also developing geometry. He had now begun to search through works on "mathematical practices of humans" and discovered a book called The Nature of Mathematical Knowledge (Kitcher, 1983). This book defined 


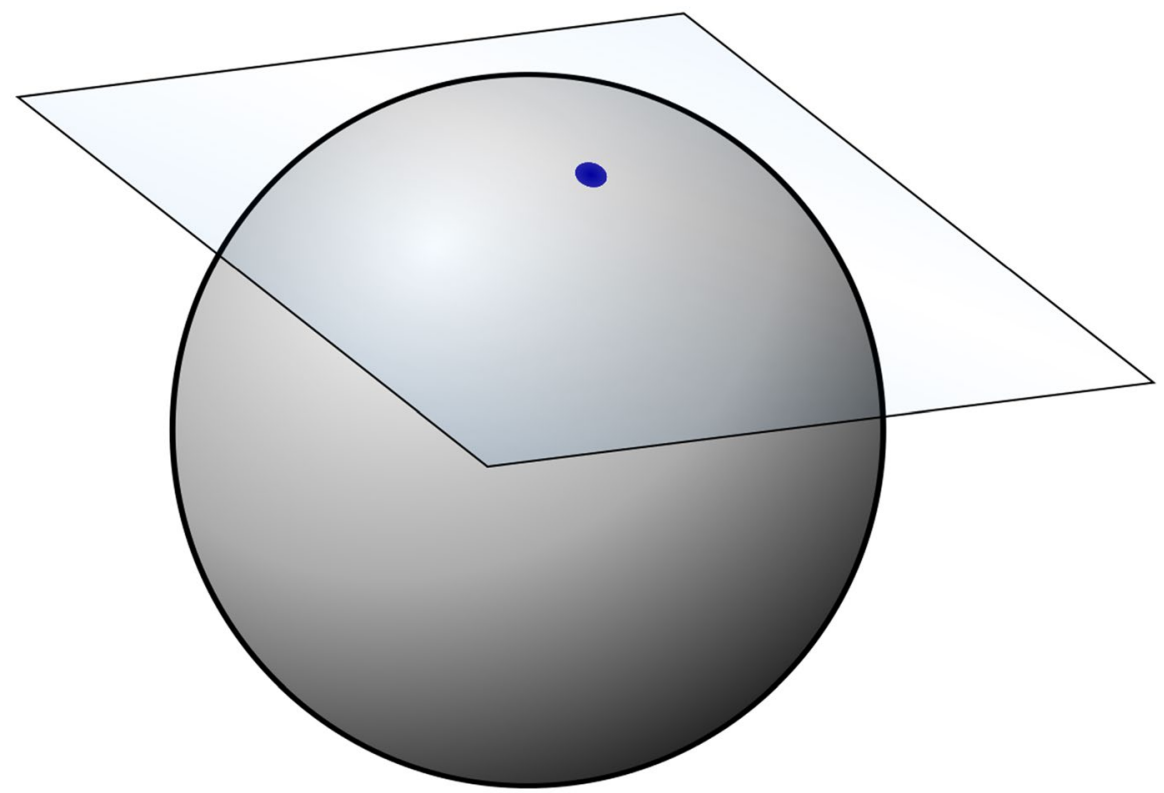

Fig. 1 Geometrical tangent vectors or Tangent space at a point $\mathrm{x}$ on the sphere (courtesy Wikipedia)

mathematical practice to be a 5-tuple $(\alpha, \beta, \gamma, \delta, \varepsilon)$ where $\alpha$ was "language of practice", $\beta$ was "meta-mathematics", $\gamma$ was "questions", $\delta$ was "reasoning" and $\varepsilon$ was "accepted propositions." When mathematical practices changed they were replaced by a new 5-tuple $\left(\alpha^{\prime}, \beta^{\prime}, \gamma^{\prime}, \delta^{\prime}, \varepsilon^{\prime}\right)$. However the book on the plasma-net too had been edited and made devoid of any concrete examples, so it was difficult to known how $\alpha$ became $\alpha$ ' etc. Alpha asked the plasma intelligence unit to construct the timeline of practices from Minkowskian geometry to the String theory revolution and produce the values of the 5-tuples. When the report arrived alpha experienced the first migraine of his life when he saw that two hundred years of mathematical practice had been distilled into one line of shifting sub-scripts and super-scripts in increasingly convoluted tensor notation. The appended note read, " $\varepsilon=\mathrm{a}$ tensor is really a special case of a geometric object." " $\varepsilon$ ' = Tensors can be bundled."

Alpha posed the question to himself "What is a geometric object? What are the different types of geometric objects that have been around in the world besides planets, light, black holes and gravity?" More pointedly, he asked - what are the objects that are constructible using sensorimotor skills on mechanical hand held devices. The Minkowskian rabbit hole also led to the discovery of the only diagram available in the plasma-net (Fig. 1).

From this clue alpha construed the notion of tangents as a geometric object that had special properties- the tangent space resembled a plane; and it seemed that tangents could be bundled together using the Hermitian language of tensors. Did these represent a family of geometric objects that could be constructed using a mechanical device? Could planes be tangential to other geometric objects besides spheres? What would be doing the measuring in the Minkowskian metric? The Lorentz 
transformation equations had four co-ordinates- three for space and one for time. To alpha, it seemed to be a bit of a stretch (pun intended) to think of time being dilated and being measured at the same time. There was no way he could visualize this, let alone imagine it being measured physically. It seemed as if his mathematical training had given him no foregrounding in thinking through the diagram using first principles of Euclidean geometry- a thought that seemed to lurk during his search for meaning.

\section{The Lorentzian Rabbit Hole: The Third Year}

At this stage, alpha gave up and took a yearlong break to follow his pursuit in B.H.E voyeuristic ethnography. The incubating ideas in alpha's sub consciousness found an illuminative moment when one of the voyeuristic documentaries series produced a film on "Primitive Scholarship of Mathematicians in the Common Era." In the documentary, there were several screen shots from different mathematics periodicals. They contained what looked like the Lorentz transformation equations with time dilation in it (Fig. 2), in addition to connections with Hermitian operators (Fig. 3). This had been the topic of his first mathematics course and suddenly turned the key in the proverbial mind lock.

Alpha realized that spinors worked like tensors but rotated the co-ordinate system in place differently, typically in reverse orientation. More importantly, he noticed a tool used to draw an object called a circle in the primitive caricature of "squaring the circle." Circles and lines it seemed formed the basis of hand held sensorimotor geometry! He continued his quest for the following years in the pursuit of the question: Did Euclidean geometry mean working with circles and lines? Would Alpha be able to develop Euclidean Geometry from scratch independently now that he had rediscovered its basic tool and the two mathematical objects (circles and lines) needed to construct the Euclidean edifice of 465 propositions in the Thirteen books of The Elements?

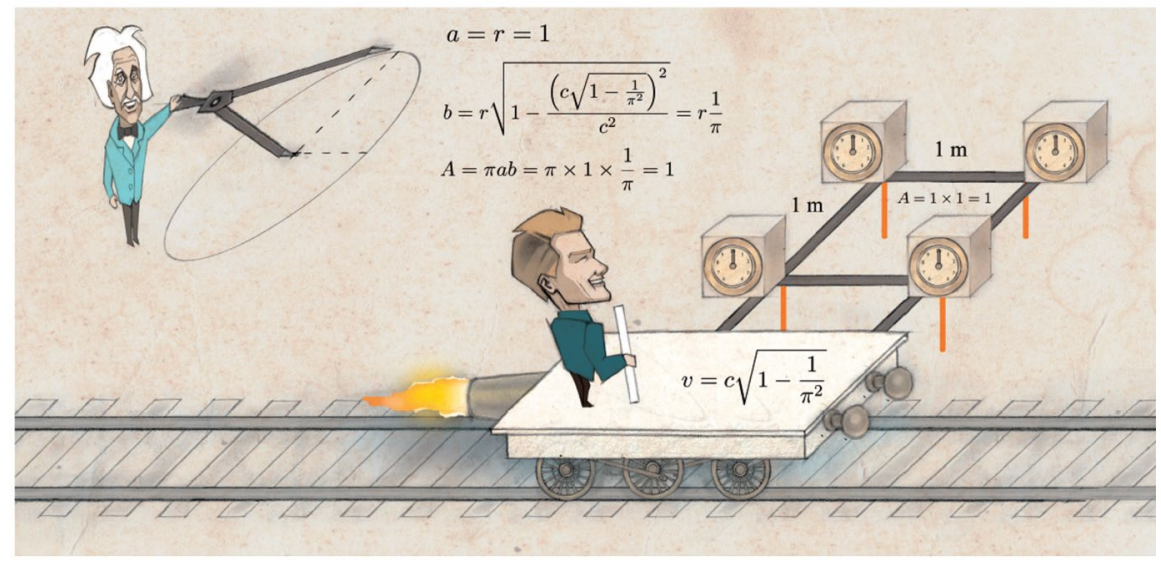

Fig. 2 Squaring the circle relativistically (Haug, 2021). Reprinted courtesy The Mathematics Enthusiast 
There is yet another way of obtaining this result, namely by using properties of two-component spinors. Any past null vector $(t, x, y, z)$ with $t<0, t^{2}-x^{2}-y^{2}-z^{2}=0$ can be represented as a hermitian matrix which is minus the product of a two-component spinor $(a, b)$ with its conjugate (see Veblen (4)). Thus,

$$
\left(\begin{array}{ll}
t-z & x+i y \\
x-i y & t+z
\end{array}\right)=-\left(\begin{array}{ll}
\bar{a} a & \bar{a} b \\
\bar{b} a & \bar{b} b
\end{array}\right) .
$$

A direction along the past light cone is then uniquely associated with the corresponding spinor ray, i.e. with the ratio $\lambda=b / a$. Now the points of the light cone at time $t=-1$ constitute a sphere $\mathscr{S}$, whose equations are

$$
x^{2}+y^{2}+z^{2}=1 ; \quad t=-1 .
$$

The field of vision of a stationary observer at the origin may be conveniently represented by this sphere. But $\mathscr{S}$ may be projected stereographically from the point $(-1,0,0,-1)$ into the plane $z=0, t=-1$, with the point $(-1, x, y, z)$ projecting into $(-1, x /(1+z), y /(1+z), 0)$. This plane may be taken as the Argand plane of the complex number

Fig. 3 Equations of a relativistically moving sphere (Penrose, 1959) Reprinted courtesy the Cambridge Philosophical Society

\section{Betas Physical Journey into Lost Worlds: Two Years Later}

Beta began her journey into answering Aleph 1's question by requesting a special permit to visit the Mutant wastelands of Xinjiang (formerly known as Western China). Aleph 1 helped her with obtaining the permits necessary and commissioned two specially trained thetas to accompany her on this journey. Beta and the two thetas arrived in the city of Kashgar, which had become the southeastern frontier of the Gobi desert that enveloped most of former China. Beta wanted to find mutants from Aleph 1's generation with the hope of learning their oral histories. Beta thought "If my teacher had access to real math books, so would people born around that time period." Life expectancy in the Mutant wastelands was 48, with most perishing due to malnutrition. One of the leaders in the Aldebaranian Politburo had justified the state of affairs in the wastelands with a famous quote attributed to Stalin in the B.H.E "One death is a tragedy, a million deaths is a mere statistic." His hope was that the million or so mutants would eventually perish and be remembered as a statistical fact by future iterations of society. The birthrate in the Mutant wastelands was well below the death rate and life expectancy was shortening with each generation. In time the quote would be equated with both prophesy and truth. Since the only official office was the Census and Famine Generation Bureau of Wasteland Affairs, this was Beta's first official stop. The alphacrat in charge was not very helpful - a posting in this remote part of the world was a punishment incurred for violating the existing Aldebaranian code of ethics elsewhere. The alphacrat had two more years to complete and was in no mood to do anything that would diminish his chances of moving back to a more idyllic place.

Beta: Would it be possible to get a map of the Wastelands with any known settlements? This would help me in locating mutants who might be able to help me. 
Alphacrat: You seem like an intelligent alpha- why are you wasting your time here? We have nothing but mortality statistics, which is the only thing the Aldebaranian Politburo is interested in.

Beta: I am not an alpha- I am a mutant alpha-beta and this is part of my capstone mathematics course for me to advance towards the Mother Bee qualification for university teaching.

Alphacrat: You will fit right in with all the other mutants here provided they don't kill you first.

(Muttering)... What a waste of the Diversification Act.

Beta: Please - any map will do. There is nothing on the plasma-net nor on the Photo-plasma. I do know that Mother Bee is given three commendation slips where she can nominate alphacrats for advanced courses in Aldebaranian Management. I would be happy to let her know you helped me with my assignment.

Alphacrat: (Computing quickly). You don't say. Why didn't you tell me that a Mother Bee was teaching your capstone course? Let me see what I can muster up in the old filing cabinets that are in underground storage. I could simply find you one of the boxes that are meant to be destroyed but we haven't done that yet because of the directive to first photo-plasma it and save it in the Dark plasma-net.

Beta: Did you say there is a Dark plasma-net?

Alphacrat: What are they teaching you young people these days. Yes, there is a Dark plasma-net that is only accessible by the Politburo. Even Mother and Father Bees need special permission to access it.

Beta: When can I have the box?

Alphacrat: Tomorrow.

The alphacrat was true to his word and produced an old box full which has maps, folders, remnants of books, rocks and a stern warning. "You have one day to return everything. Don't get smart and steal anything! Every item is part of our inventory here."

\section{Pandora's Box 2.0}

Pandora's box (noun): A source of many unforeseen troubles or problems, named after the first woman on earth commissioned by Zeus, the Greek God through Hephaestus- the God of fire and sculpture.

Beta stumbled upon two maps from two different time periods. One was an early map from 12 A.H.E, which seemed similar to existing maps she had seen, but the second more worn out map had an acronym A.C.E, which she did not quite grasp. Perhaps it was a misprint and $\mathrm{C}=\mathrm{H}$ ?

No one in the Aldebaranian society had even heard of something known as the Common Era since the world before Huxley was simply not known to exist for most of the inhabitants living in the fifth iteration of huxleyfication. There were crumbling magazines, one whose cover (Fig. 4) would need plasma analysis for reconstruction.

Fig. 4 Cover of The Crisis, vol.1, no.5 (edited by W.E. Burghardt Du Bois, 1911) 


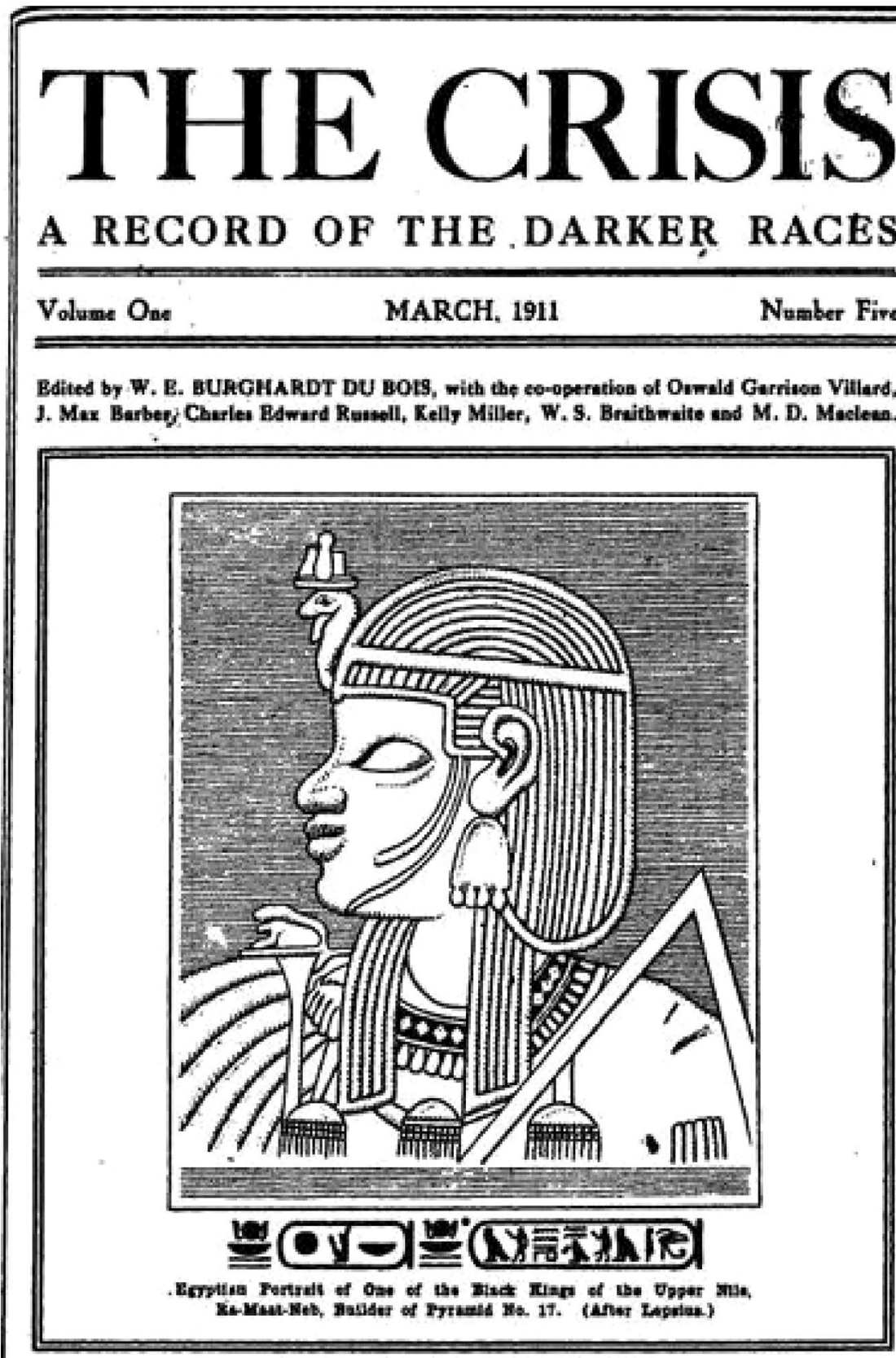

PUBLISHED MONTHLY BY THE

National Asociation for the Advancement of Colored People AT TWENTY VESEY STREET NEW YORK CITY 


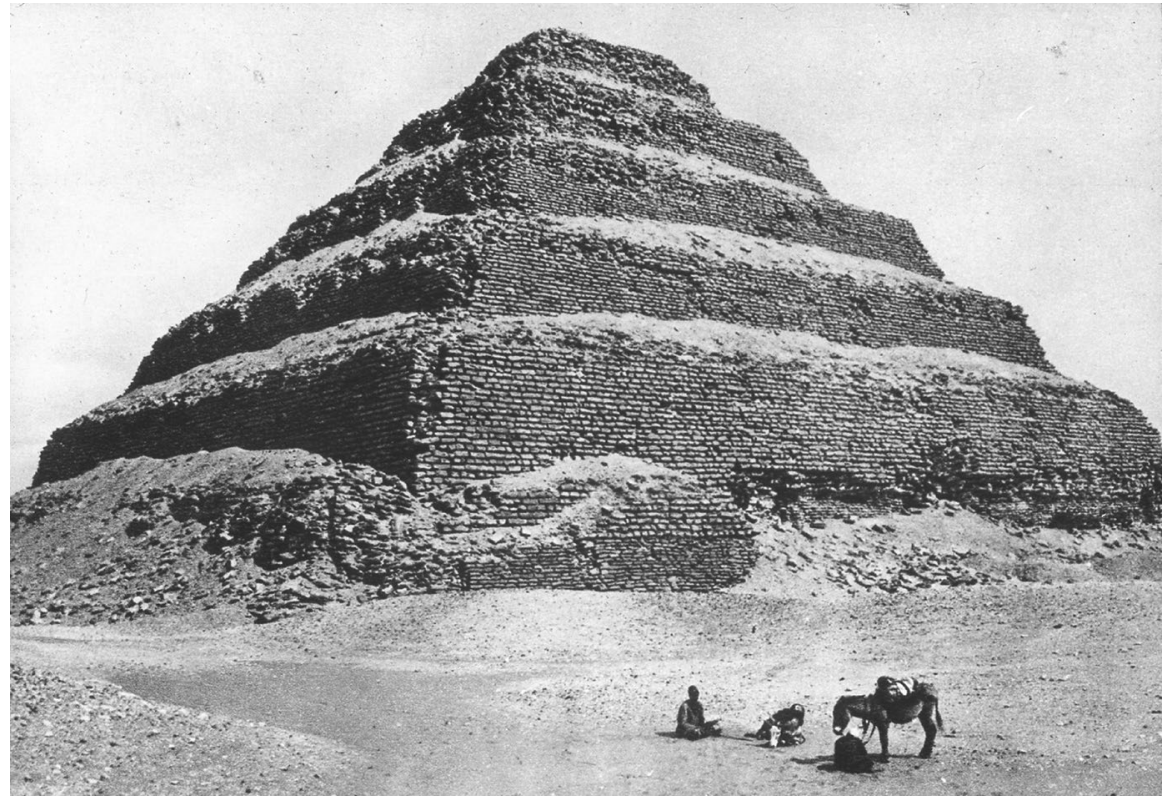

Fig. 5 Step Pyramid of Djoser (Zoser) (undated before 1923). Lantern Slide Collections: Egypt. Sakarra. View 12: Egyptian Old Kingdom. Step Pyramind of Zoser 3rd Dynasty. Property of the Brooklyn Musuem Archives. Public Domain

Many of the pages crumbled upon any touch. She felt the cover held a lot of information and was fascinated by the title "The Crisis" (Du Bois, 1911). The rest of the box held stone fragments, which seemed deliberately broken. She photo-plasmed the cover to Mother Bee, whose first reaction when it entered her consciousness was a gasp. She could see both the image of an ancient pyramid as well as the Eye of Horus. One of the other Mother Bees who taught Ancient Huxylean history had hinted at the idea of human made stone relics that were deliberately geometric in nature. She however was unable to access the Dark plasmanet, which contained copious information about the advent of the Nubian kings in Upper Egypt and the construction of the very first pyramid at Djoser (Zoser) in 2630 B.C.E (Fig. 5).

Beta returned the box the next day at which time the alphacrat really tried to curry her favor to earn Mother Bee's commendation by mentioning two cities accessible in the Wastelands, called Satori and Qhamgin. Beta thanked him, but was anxious for the plasma reconstructed magazine cover and the maps to arrive. She was particularly fascinated by the map that had the acronym A.C.E - and on closer examination looked very different to existing maps with more land mass than expected and no evidence of the Polar seas. The reconstructed material arrived during the journey to Satori with a lengthy annotation from Mother Bee herself. The annotation read:

The A.C.E map was propaganda distributed by humans. Zululand ends at the equator and there is nothing to the north of it, just as there is nothing north of the mutant wastelands. 
The note intrigued beta. The map showed a rather large landmass north of 0 degrees, with a clearly marked river called the Nile flowing South to North to what looked like a landlocked sea. The magazine cover had fine print, which read "Egyptian portrait of one of the Black Kings of Upper Nile...Builder of pyramid No.17." What was a pyramid? The year 1911 made no sense at all to beta. Could it be a year in the B.H.E? Beta had spent her childhoid-hood in Zululand but there were never any physical trips to its frontiers. The northern frontiers of Zululand seemed like the next step to unlocking the mystery. Overlapping the two maps even though they were slightly different sizes clearly suggested places that once might have existed in the B.H.E. During these ruminations, the two thetas were busy navigating the Desert Hoover towards Satori.

\section{From Satori to ancient Nubia: The Third Year}

Satori proved to be a disappointment. The "city" had crumbling blocks of apartment buildings slowly eaten up by the sand and desert wind. She learned from several inhabitants that an underground river with brackish water helped with irrigating certain crops that in turn sustained life. The underground river was the source of conflict between the Satoris and the Qhamgins, who were nomadic and had huge herds of Bactrian camels, which repeatedly destroyed the Satorian fields. War between these two groups followed by bouts of famine had greatly reduced the population of both cities. Several migrations had taken place past the boundaries of the Wastelands into another uninhabited region purported to be marked by a never-ending wall. Beta again overlapped the two maps and saw that there was more landmass in the Mutant Wastelands than the A.H.E map indicated, and clearly mutants had migrated there according to different Satori sources. This confirmed her suspicion that the A.C.E map may in fact contain some truths, which were worth exploring. She aborted her venture into the Wastelands and returned to Aleph 1.

The meeting between Aleph 1 and Beta was highly contentious. Beta accused the Mother Bees of the Hermitian University of Free Thought of deliberately falsifying information in the photo plasma and threatened to file a complaint with the Aldebaranian Politburo. She held Mother Bee's note as the physical incriminating evidence. So far, the University had managed to exist independently of Politburo interference by creating newer branches of study in Aldebaranian policy, Aldebaranian management, Aldebaranian ideology (formerly known as critical thinking). Alphacrats who studied these areas relayed positive reports to the Politburo, who assumed that Aldebaranian order prevailed at the University. Aleph 1's goal of reconstructing the so-called "Collective Consciousness 1.0" of the B.H.E was not sanctioned by the Politburo, nor was her goal of establishing new Lyceums in the Mutant wastelands, independent of the photo-plasma and the plasma-net. Beta now knew this beyond a doubt and voicing her realization had Aleph 1 and certain other Mother Bees abuzz with fear. Their heretical views stood to be exposed unless they allowed Beta to pursue her course of proposed action. Beta made it categorically clear that she would remain mum as long as a permit was granted to visit the northern frontiers of Zululand at the Equator. The Mother Bee who taught Ancient Huxlyean history came 
to Aleph 1's rescue. She was married to a Politburo member, and could make this travel possible under the Aldebaranian codes of "Pilgrim Permit." Pilgrim Permits were exclusively granted to Politburo members to travel in areas of the planet that were no longer present on A.H.E maps. This particular Politburo member was an ageing Nubian who longed to make one last pilgrimage to his ancient homeland and pay homage to Rah, the less powerful but noble brother of the Supreme Deity Aldebaran. Although Rah's powers were forty four times less than that of Aldebaran, he nevertheless held a special place in the heart of the ancient Nubians.

At the culmination of the third year, Beta found herself with the ageing Nubian, his wife the Mother Bee of Ancient Huxleyean history who had retired, and Aleph 1 , who had resigned from her position for an appointment into the Politburo. Aleph 1 now pledged allegiance to the Aldebaranian Politburo with the sacred words "Rah will perish soon in the 1st, but Aldebaran will reign Supreme in the 11th." They traveled north of Zululand past the equator, along the unmarked river formerly known as the Nile and arrived at the base of the Step Pyramid of Djoser. Beta and both the former Mother Bees gasped at the structure. They had never imagined a handmade structure built in the scale that was present before them. To their astonishment, there were bigger pyramids as they moved further north. During their journey, the ancient Nubian revealed to Beta and the two former Mother Bees that sensorimotor geometry was both invented and perfected by the Nubians four Millennia before the Common Era (B.C.E), with nothing other than a rope that formed a right triangle. This and their faith in the power of Rah and his older brother Aldebaran was the basic tool for handcrafting the structures around them. Beta realized that the structures around her were more than 5000 years old and still standing in homage to Rah. She also understood the significance of the cover of "The Crisis" and experienced the revelation "Hand held sensorimotor geometry originated with the Nubians and was used for sacred purposes." This revelation led her to a lifelong pursuit of residual sensual geometry in nature.

\section{A.H}

Fourteen years have passed since the journeys of Alpha and Beta, who are both now Father Bee and Mother Bee respectively in the Hermitian University of Free Thought. When the two met after their respective journeys, they clashed intellectually on what was the true origin of sensorimotor Geometry. Alpha had built a compass and started to construct "Euclidean objects" and even think about what they meant abstractly and tried to coin new rules. Beta did not push her revelation that the Nubians were the true sensorimotor Geometers. She enjoyed arguing with Alpha always chiding him not to become too abstract, lest he loose himself the way the humans did and eventually perish in the misery of their own logic. The intellectual clashes led to a strong emotional bond, which resulted in their Union, sanctified by the ancient Nubian and the two former Mother Bees. Alpha continued to develop Euclidean geometry more and more abstractly, Beta in the meantime bore many humanoid alpha-beta mutants who enjoyed worshipping the sun with their mother, and observing plants and trees pollinated by bees. Beta had been given a hive box 
full of bees as a wedding gift from the ageing Nubian- and the only copy of a prehistoric article (Maclaurin, 1743) in which she learned that bees possessed natural geometric instinct and could collectively channel this into creating perfect geometric objects with a sensual dimension of sweet tasting honey. She taught her children to keep bees and instilled in them the awareness that honey Bees were the only true professors of sensorimotor Geometry. The rest was hubris!

\section{Coda}

This chapter was written in the creative style of a provocative thought experiment that takes place in a Huxleyean future (late twenty-first century our time)- where straight-edge and compass, and any other type of sensorimotor construction in geometry was no longer possible due to all learning taking place virtually. In this future, knowledge had been "huxleyed"- meaning only what is essential for day to day living was available for $99.99 \%$ of the population and brainwashed into them, and the remaining $0.01 \%$ are offered a selective glimpse at "higher learning" through intellectually challenging exercises. In one such classroom, when challenged by a teacher on whether there once was a geometry that could be done entirely by hand (physically), two protagonists tried to retrace the story of geometry. The protagonist alpha went backward virtually putting together bits and pieces of an incomplete mosaic of operators and diagrams that led him to the awareness of a compass. Beta traveled physically looking for evidence of what geometry once was- her journey leading her back to 4000 B.C.E and the ancient cities of Kashgar (in the former Xinjian Kingdom of Central Asia) and Sesebi, Amaram, and Aniba (in the former Nubian kingdom in Ancient Egypt; and presently in South Sudan). The question is what does such a thought experiment mean for the learning of mathematics in terms of existing philosophies of technology? This is the topic of discussion.

Borgmann (1984) argued that the culture of technology can be characterized as a transformation of usage of traditional things with devices, as understood according to the device paradigm. So, in our case, traditional activities in geometry that were once done with paper, pencil, straight-edge and compass became replaced by digital software which retained some elements of the traditional geometry. However, mathematics is also the science of abstract thought, and traditional geometry is easily replaceable with mathematical operators- symbols loaded with meaning that soon become another commodity. The commodification of traditional geometry with replacements like software and operator notation leads to a growing focus on specialization in order to tend to the ever-growing sophistication present in the software or mathematical notation. Alpha, Beta and the other students were consumers of plasma-net services under the guise of education, available instantaneously in a Huxlyean world, devoid of all meaning. This is analogous to contemporary students relying on Google or Wikipedia to "instantaneously" locate a piece of knowledge " $\mathrm{k}$ " without really understanding what the genesis of " $\mathrm{k}$ " was or what it means and how it could be applied. Finding a piece of information " $\mathrm{k}$ " on the internet is increasingly equated with understanding it. Sriraman, Roscoe \& English (2010) placed "mathematics" 
within Borgmann's device paradigm to argue that a society that embraces such a paradigm should expect the commodity of computational power to become more and more ubiquitous and instantaneous with the danger of the machinery of computational power turning away from the user, shrinking in size, and to grow ever more concealed. For example, modern graphing calculator or mathematical software that does symbolic manipulations devoid of meaning presents the risk of not knowing the mathematical foundations of basic functions. These include the trigonometric functions, logarithm and exponential functions, approximations of transcendental numbers like $\pi$ and $\varphi$ - all of which are computed by algorithms that rely on their mathematical series representations, with attention to fast convergence. The implications of this for the future are crystal clear.

There is an ever-growing sophistry in the way popular mathematics is portrayed in the media, which has permeated university curricula. The watering down of the general mathematics courses required for a basic liberal arts degree has led to mathematics consumed in the guise of "Math Appreciation", akin to Music Appreciation or Art Appreciation. In other words, to consider the inner workings of mathematics as too sophisticated and unnecessary for the general public results in its continual concealment creating a hierarchy within society. Technologically saturated environments have already created opportunities for creative individuals to engage in phlegmatic and malevolent creativity. The world prophesized by Aldous Huxley is already coming true with the advent and unchecked use of AI for mass manipulation and social engineering as Brexit and the election of other populist leaders has indicated. On the other hand, keeping knowledge and communication out of the reach of masses has also served to preserve autocratic regimes. In either case, it would be disastrous for the future generations of children if education became the next victim, with mass manipulation of learning in order to stratify future society through AI, huxleyfication or otherwise.

\section{Appendix: A Glossary of Terms (alphabetized)}

1. Aldebaran: Derived from the Arabic al Dabarān ("الدبران"), which literally means "the follower." It is a giant star designated as $\alpha$-Tauri in the zodiac Taurus constellation about 65 light years from the Sun. It is used here for satirical purposes to denote the followers in the pseudo Huxleyean world, as a homage to the ancient Nubians who worshipped our Sun.

2. Calabi-Yau manifolds: A mathematical object used in super string theory to posit the existence of ten dimensions in the geometry of the universe, which include six space dimensions called the Calabi-Yau space.

3. Gondwanaland: A supercontinent in the Neoproterozoic epoch (about 550 million years ago) that began to break up during the Jurassic (about 180 million years ago).

4. Hermann Minkowski (1864-1909): A German mathematician who was the teacher of Albert Einstein, and developed space-time geometry also known as Minkowskian geometry that served as the basis of the theory of special relativity. 
5. Higher Arithmetic (The): A classical text on number theory written by Harold Davenport (1907-1969). Davenport had been a research student of the eminent J.E. Littlewood, and was the doctoral supervisor of John H. Conway (19372020). Conway passed away due to complications from Covid-19, a pandemic that confronted the world in 2019 of the common era.

6. Homeomorphism: In mathematics, a homeomorphism is a continuous map between topological spaces that also has an inverse map. Colloquially one can transform a coffee mug into a donut and vice-versa.

7. Kalaripayyattu: An Indian martial art that originated in the Indian state of Kerala.

8. Laws of Manu: The Manusmriti, is an ancient legal text, part of the Dharmaśāstras of Hinduism. It was one of the earliest Sanskrit texts translated into English by Sir William Jones.

9. Lorentz transformations: Equations with 6-parameters of linear transformations to move from a frame in the space-time coordinate system to to another frame which remains at a constant velocity relative to the former.

10. Plasma: Excluding dark matter and the even more elusive dark energy, plasma is the most abundant form of ordinary matter in the universe.

11. String theory: A branch of mathematics which was considered a plausible approach to the unification of relativity with quantum mechanics. However this approach has been more or less abandoned when its prediction of certain particles were not found by the large Hadron collider.

12. Tahtib: A traditional method of stick fighting that originated in the Old Kingdom of Egypt (2686 B.C.E - 2181 B.C.E). In modern Egypt it is practiced as a folk dance form. The traditional martial art is still demonstrated by Nubians in the Aswan region of modern Egypt.

13. Wanderjahre: A time of travel after the completion of apprenticeship training (typically in the hand crafts).

14. W.E. Burghardt Du Bois: William Edward Burghardt Du Bois (/dju:'bors/dewBOYSS; February 23, 1868 - August 27, 1963) was a Professor of History, an American sociologist, early civils right activist, historian and the founders of the Pan-Africanist movement. Du Bois was one of the founders of the National Association for the Advancement of Colored People (NAACP) in 1909.

Acknowledgements The author is grateful to the three anonymous referees - the mathematicians from Canada, Mozambique and France for their thoughtful reviews which helped sharpen the mathematical and satirical scope of this essay.

\section{References}

Borgmann, A. (1984). Technology and the Character of Contemporary Life. The University of Chicago Press.

Davenport, H. (1952). Higher Arithmetic. Hutchinson's University Library.

Du Bois, W.E.B. (1911). The Crisis: A record of the darker races. 1(5). New York City: National Association for the Advancement of Colored Peoples. 
Haug, E. (2021). Squaring the circle and doubling the cube in space-time. The Mathematics Enthusiast, $18(1 \& 2), 59-77$.

Huxley, A. (1932). A Brave New World. Chatto \& Windus.

Kitcher, P. (1983). The Nature of Mathematical Knowledge. Oxford University Press.

Maclaurin, C. (1743) Of the Bases of the Cells wherein the Bees deposit their Honey. Philosophical Transactions 42: 565-571.

Penrose, R. (1959). The apparent shape of a relativistically moving sphere. Proceedings of the Cambridge Philosophical Society, 55, 137-139.

Sriraman, B., Roscoe, M., \& English, L. (2010). Politicizing mathematics education. Has politics gone too far? or not far enough? In B. Sriraman \& L. English (Eds.), Theories of Mathematics Education: Seeking New Frontiers (pp. 621-638). Springer Science: Berlin/Heidelberg.

Publisher's Note Springer Nature remains neutral with regard to jurisdictional claims in published maps and institutional affiliations. 